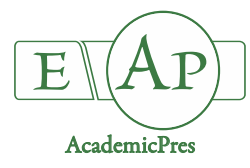

\title{
Some Pomological Properties of Promising Seed Propagated Walnut Genotypes from Inner Turkey
}

\author{
Aysen $\mathrm{KOC}^{1}$, Hakan $\mathrm{KELES}^{1}$, Sezai ERCISLI ${ }^{2 *}$ \\ ${ }^{1}$ Bozok University, Faculty of Agriculture, Department of Horticulture, 66100 Yozgat, \\ Turkey;aysen.koc@bozok.edu.tr; keles.hakan.1986@gmail.com \\ ${ }^{2}$ Ataturk University, Faculty of Agriculture, Department of Horticulture, 25240 Erzurum, Turkey; sercisli@gmail.com ( ${ }^{*}$ corresponding author)
}

\begin{abstract}
In this study, fruits from seed propagated walnut (Juglans regia L.) trees were collected two consecutive years in harvest seasons in Yozgat province in Turkey. Considering two years results, promising five genotypes were determined as cultivar candidate. In the promising genotypes, nut weight ranged from 12.55 (Y11) to $15.08 \mathrm{~g}$ (Y15), kernel weight ranged from 5.23 (Y11) to $7.34 \mathrm{~g}$ (Y15) and kernel ratio varied between 41.67 (Y11) to $50.84 \%$ (Y1), respectively. Linoleic acid was the only polyunsaturated fatty acids and oleic, palmitoleic and gondoic acids determined as major monounsaturated acids ranged from 30.36 to $48.43 \%, 0.05$ to $0.14 \%$ and 0.22 to $0.29 \%$, respectively. Propylparaben was the major phenolic acid among the determined phenolic acids in fruits of all five promising genotypes and Y16 had the highest amount of propylparaben (128.08 $\mathrm{mg}$ per $\mathrm{kg}$ ) in its kernel. Malic and tartaric acid were the major organic acids in walnut kernels ranged from 47.88 to $78.51 \mathrm{mg}$ per $100 \mathrm{~g}$ and 30.27 to $49.60 \mathrm{mg}$ per $100 \mathrm{~g}$, respectively. L-ascorbic acid was the another organic acids in walnut kernels ranged from 10.71 to $19.71 \mathrm{mg}$ per $100 \mathrm{~g}$. Citric acid was non-determined in kernels of Y1, Y14 and Y15 but determined at kernels of Y11 and Y16 as 4.51 and $7.55 \mathrm{mg}$ per $100 \mathrm{~g}$, respectively. It was determined that the oxalic, malonic, succinic, maleic and fumaric acid contents varied between 8.39-12.08 mg per $100 \mathrm{~g}$, 6.02-9.19 mg per $100 \mathrm{~g}, 2.86-5.32 \mathrm{mg}$ per $100 \mathrm{~g}, 0.26-3.00 \mathrm{mg}$ per $100 \mathrm{~g}$ and $0.26-0.58 \mathrm{mg}$ per $100 \mathrm{~g}$, respectively.
\end{abstract}

Keywords: chemical; genotype; Juglans regia L.; morphological and pomological properties

\section{Introduction}

Plant genetic resources are one of the most important natural richness of any country and they provide particularly food and medicine for people's livelihoods. Plant genetic resources are also an important source of some rare genetic traits such as resistance to some plant pest and diseases, resistance to some abiotic and biotic environmental conditions (Halasz et al., 2010; Ersoy et al., 2017; Guliyev et al., 2018; Gunduz and Ozbay, 2018).

The overall aim of plant and animal production is to obtain high yield from both sources. Environmental and genetic background are strongly influence this trait. Thus plant genetic resources are accepted one of the ready breeding material to obtain high yield in different plant species (Sehirali and Ozgen, 1987; Serce et al., 2010; Ersoy et al., 2018).

Juglans regia, 'Persian' or 'British' walnut is the most valuable walnut species with great economic importance among eighteen walnut species around the world (Leslie and McGranahan, 1988). It is estimated that Turkey has over 5 million native, obtained from seeds, walnut trees (Keles et al., 2014). The country is also one of the most important diversity center of Juglans regia (Akca et al., 2009). In terms of production amount, Turkey produce 210.000 tons walnut annually and ranked $4^{\text {th }}$ after China (1.925.403 tons), USA (571.526 tons) and Iran (349.192 tons) (FAO, 2018).

In Turkey, commercial walnut orchards are available and new orchards are being established. However the majority of walnut trees propagated by seeds in most of the growing regions in Turkey and they can be used not only their fruits but also for timber production. Continuous seed propagation of walnut trees in different agro-climatic conditions in Turkey fora a long time revealed promising walnut genetic resources for walnut breeding programs (Asma, 2012). To obtain new walnut cultivars, cross breeding in general has been used however selection among natural seed propagated seedlings could be used as effectively to determine superior genotypes (Keles et al., 2014). Selection among native growing seed propagated genotypes is an easier and faster way to obtained new cultivar. In fact famous Turkish walnut cultivars such as 'Şebin', 'Bilecik', 
'Kaman 1', 'Şen 1', 'Maraş 18', etc. have been selected among these natural populations (Akca et al. 2012).

Walnut kernels contain various beneficial contents such as fatty acids, mineral compounds, protein, carbohydrate, vitamin, phenolic acids and organic acids (Mitrovic et al., 1997). Previously a wide number studies has been carried out on fat, fatty acids and tocopherol content of seed propagated walnut genotypes (Caglarirmak, 2003; Ozkan and Koyuncu, 2005; Gharibzahedi et al., 2014; Keles et al., 2014; Poggetti et al., 2017). However limited number of study has been conducted on seed propagated genotypes related to phenolics and organic acid content. Thus more data are needed about the nutrient contents of walnut fruits.

\section{Materials and Methods}

\section{Plant material}

The study was carried out in 2017-2018 on naturally seed propagated genotypes found in the villages of Hisarbey and Akçakişla belonging to Yozgat province. Many walnut trees are naturally grown or cultivated in most of the region of Yozgat and Hisarbey and Akcakisla villages are very famous with seed propagated walnut trees. The aim of this study was to determine the promising genotypes selected from to the villages and provide more information about morphological, pomological and chemical properties of naturally grown walnut trees. At the beginning of the study, pre-selection was done according to the general condition of trees such as disease and pest situation, productivity and nut quality and totally 16 walnut genotypes were found suitable for research. Morphological and pomological properties were examined according to Keles et al. (2014). Promising genotypes among all genotypes were determined by considering weighted ranking method including the average nut weight, kernel ratio, ease of kernel's separate from the shell, kernel colour, anthracnose and codling moth situation of genotypes. The nut traits were measured on randomly selected 20 nuts (Keles et al., 2014). After the use of weighted ranking method, 5 genotypes were determined as superior among all genotypes.

\section{Extraction method for phenolic acids and organic acids}

The walnut fruit samples have been extracted according to the method described by Liu et al. (2010). Dried, walnut fruits milled into a fine powder. A $2.0 \mathrm{~g}$ of walnut fruit powder extracted three times with $20 \mathrm{ml}$ of aqueous ethanol $(80 \%)$ in an ultrasonicator bath at $40{ }^{\circ} \mathrm{C}$, for $15 \mathrm{~min}$ for each extraction. The obtained extracts from three extractions have been combined. After the removal of ethanol using rotary evaporation, the extract dissolved in 10 $\mathrm{ml}$ methanol, followed by filtration through a $0.45 \mu \mathrm{m}$ filter. After this, the clear solution placed in the glass vial of HPLC and the sample was analysed by HPLC-DAD.

\section{HPLC analysis for phenolic acids}

Phenolic acids (gallic acid, protocatechuic acid, phydroxybenzoic acid, vanillic acid, caffeic acid, chlorogenic acid, syringic acid, and ferulic acid) separation was performed using HPLC autosampler system model LC$20 \mathrm{AT}$, on a Inertsil $\mathrm{C}_{18}$ ODS-3 column ( $5 \mu \mathrm{m}$ particle size,
$4.6 \mathrm{~mm} \times 250 \mathrm{~mm}$, Japan) at $25^{\circ} \mathrm{C}$. A binary solvent system employed consisting of methanol:water:formic acid (10:88:2, v/v) as solvent $A$ and methanol:water:formic acid $(90: 8: 2, \mathrm{v} / \mathrm{v})$ as solvent B. The detection monitored at 280 nm (Ozturk and Tuncel, 2011) using an SPD-M20A photodiode arrays (PDA) detector (Shimadzu, Japan).

\section{HPLC analysis for organic acids}

Organic acids (oxalic, tartaric, formic, malic, L-ascorbic, malonic, maleic, citric, succinic, fumaric) acids separation was performed using HPLC autosampler system model LC20AT, on an Inertsil C18 ODS-3 column ( $5 \mu \mathrm{m}$ particle size, $4.6 \mathrm{~mm} \times 250 \mathrm{~mm}$, Japan) at $40{ }^{\circ} \mathrm{C}$. A $0.0125 \mathrm{M}$ $\mathrm{H}_{2} \mathrm{SO}_{4}$ was used as mobile phase. The detection monitored at $214 \mathrm{~nm}$ (Bhandari and Kawabata, 2004) using an SPDM20A photodiode arrays (PDA) detector (Shimadzu, Japan).

\section{Oil extraction}

Oil extraction was performed based on the method of Bligh and Dyer (1959). Oils of $20 \mathrm{~g}$ fruits were extracted using hexane solvent for $1 \mathrm{~h}$ using automatic Soxhlet equipment (Gerhardt Soxtherm) and triplicate analysis were reported for each genotype. The residue was dried until a constant weight was observed. Boron trifluoride/methanol was used for the preparation of fatty acid methyl esters (FAMEs) (AOAC, 1990).

\section{Fatty acids analysis}

Fatty acid methyl esters (FAMEs) contents were analyzed using gas chromatography, model GC-6890N coupled with the mass spectrometer, model MS-5973 MSD (mass selective detector) as described by Tariq et al. (2011). The separation was performed on a capillary column DB5MS (30 m× $0.32 \mathrm{~mm}, 0.25 \mu \mathrm{m}$ of film thickness). The conveyor gas was Helium with a flow rate of $1.5 \mathrm{~mL} / \mathrm{min}$. The column temperature was set to 120 to $300{ }^{\circ} \mathrm{C}$ at the rate of $10{ }^{\circ} \mathrm{C} / \mathrm{min}$. The temperature of both injector and detector was programmed at $250{ }^{\circ} \mathrm{C}$. A sample volume of $0.1 \mu \mathrm{L} \mathrm{RSOB}$ in $\mathrm{CHCl}_{3}$ was injected using a split mode, with the split ratio of $1: 10$. The mass spectrometer was set to scan in the range of $\mathrm{m} / \mathrm{z} 50-550$ with electron impact (EI) mode of ionization.

\section{Statistical analysis}

All results were tested by SPSS 20.0 for Windows program. The differences between the means were compared using the Duncan test $(p<5 \%)$.

\section{Results and Discussion}

Table 1 and 2 show some morphological and pomological characteristics and pests and disease situation of all genotypes. Promising genotypes are shown in Table 1 and 2 in bold.

\section{Morphological characteristic}

As shown in Table 1, all genotypes showed strong or very strong tree vigor. Nine genotypes were determined as upright, five genotypes were spreading and two genotypes had semi-upright growth habit (Table 1). 
1096

Trunk circumferences were ranged from 90 to $263 \mathrm{~cm}$ among genotypes. Leaflet shape of genotypes showed some differences and eleven genotypes had elliptically, three genotypes had narrow elliptic and two genotypes had narrow elliptic leaflet shape (Table 1). Additionally, five genotypes were determined as anthracnose free and no codling moth was found in nuts of eleven genotypes (Table $1)$.

\section{Pomological characteristics}

Considering average nut weight, kernel ratio, ease of kernel's separate from the shell, kernel colour, anthracnose and codling moth situation of genotypes, five genotypes were determined as promising. In the selected genotypes, nut weight ranged from $12.55 \mathrm{~g}$ (Y11) to $15.08 \mathrm{~g}$ (Y15), kernel weight ranged from $5.23 \mathrm{~g}$ (Y11) to $7.34 \mathrm{~g}$ (Y15) and kernel ratio determined between $41.67 \%$ (Y11) to $50.84 \%$ (Y1) (Table 2). Shell thickness and nut weight were between 12-18 g, which ideal size for walnuts. Ideal walnut kernel weight should be 6-10 g and kernel should be light in colour (McGranahan and Leslie, 2012). In this study, all selected genotypes showed light kernel colour and two genotypes showed ease to separate kernel from shell, three genotypes showed very ease separation from shell. Moreover, shell thickness ranged from $1.20 \mathrm{~mm}$ to 1.56 $\mathrm{mm}$, and an empty kernel percent range from 0 to $6 \%$. In terms of some nut and kernel properties, selected genotypes can be considered as good quality. In previous selection studies carried on different region in Turkey, nut weight varied from $7.82 \mathrm{~g}$ to $18.74 \mathrm{~g}$, kernel weight ranged from $4.04 \mathrm{~g}$ to $9.00 \mathrm{~g}$, kernel ratio varied from $42.88 \%$ to $67.14 \%$ and shell thickness varied from $0.58 \mathrm{~mm}$ to $2.03 \mathrm{~mm}$ (Akca and Koroglu 2005; Keles et al., 2014). The results of our study are similar to previous studies.

Fatty acids

Fatty acids analyses results are shown in Table 3 . Linoleic acid (18:2) was the dominant fatty acid (between
41.48 and $58.35 \%$ ) in all kernels of superior genotypes. This result is in accordance with the literature (Gharibzahedi et al., 2014; Pogetti et al., 2017). Linoleic acid was followed by oleic (C18:1), palmitic (C16:0), stearic (C18:0), gondoic (C20:1), arachidic (C20:0) and palmitoleic (C16:1) acids, respectively (Table 3 ). Some of these fatty acids are named as saturated fatty acids and palmitic acid (C16:0), stearic acid (C18:0) and arachidic acid (C20:0) are classified in this group and the others are named as unsaturated fatty acids. Walnut kernels are poor in saturated fatty acids while rich in unsaturated fatty acids that contain polyunsaturated and monounsaturated fatty acids which are valuable for human diet (Nettleton, 1995). In present study linoleic acid was the only polyunsaturated fatty acids and oleic, palmitoleic and gondoic were the monounsaturated acids ranged from 30.36 to $48.43 \%, 0.05$ to $0.14 \%$ and 0.22 to $0.29 \%$, respectively. In recent studies, it was stated that the amount of oleic, palmitoleic and gondoic acids ranged from 14.73 to $25.13 \%, 0.00$ to 0.25 and 0.16 to $0.18 \%$ in walnut kernels, respectively (Pereira et al., 2008; Gharibzahedi et al., 2014).

Palmitic acid was the major saturated fatty acid in kernels ranged between 5.75 and $8.27 \%$ followed by stearic acid ranged from 3.20 to $3.86 \%$ and arachidic acid ranged from 0.11 to $0.13 \%$, respectively. In previous studies, concentrations of palmitic acid ranged from 4.64 to 11.21 , stearic acid ranged from 2.56 to $5.11 \%$ and arachidic acid ranged from 0 to $0.16 \%$, respectively (Ozkan and Koyuncu, 2005; Gharibzahedi et al., 2014; Poggetti et al., 2018). The oil composition of kernels can be affected by some factors such as genotype, ecological conditions, location, harvest time etc. (Crews et al., 2005).

\section{Phenolic acids}

Phenolic compounds are important for humans and many health-beneficial effects of walnut phenolics were reported previously (Anderson et al., 2001; Fukuda et al., 2003, Polonik et al., 2003).

Table 1. Morphological characteristics, pests and disease situation of walnut genotypes

\begin{tabular}{|c|c|c|c|c|c|c|}
\hline Genotypes & Vigor & Growth habit & $\begin{array}{l}\text { Trunk circumference } \\
\qquad(\mathbf{c m})\end{array}$ & Shape of leaflet & Anthracnose & Codling moth \\
\hline Y1 & Strong & Upright & 169 & Elliptic & Scale 1 & + \\
\hline $\mathrm{Y} 2$ & Strong & Upright & 120 & Narrow Elliptic & Scale 1 & - \\
\hline Y3 & Very Strong & Spreading & 230 & Elliptic & Scale 1 & - \\
\hline Y4 & Strong & Spreading & 90 & Narrow Elliptic & Scale 2 & - \\
\hline Y5 & Strong & Upright & 160 & Elliptic & Scale 1 & - \\
\hline Y6 & Strong & Spreading & 146 & Elliptic & Scale 2 & - \\
\hline $\mathrm{Y} 7$ & Strong & Upright & 136 & Broad Elliptic & Scale 1 & - \\
\hline Y8 & Very Strong & Upright & 132 & Elliptic & Scale 2 & - \\
\hline Y9 & Strong & Spreading & 198 & Elliptic & Scale 0 & + \\
\hline Y10 & Strong & Upright & 181 & Elliptic & Scale 0 & - \\
\hline Y11 & Strong & Upright & 114 & Elliptic & Scale 1 & - \\
\hline Y12 & Strong & Semi-upright & 154 & Narrow Elliptic & Scale 0 & - \\
\hline Y13 & Strong & Upright & 133 & Elliptic & Scale 2 & + \\
\hline Y14 & Very Strong & Upright & 263 & Elliptic & Scale 0 & - \\
\hline Y15 & Strong & Spreading & 178 & Elliptic & Scale 2 & + \\
\hline Y16 & Strong & Semi-upright & 163 & Broad Elliptic & Scale 0 & + \\
\hline
\end{tabular}

$(+)$ : shows the presence of codling moth, (-): shows the absence of codling moth and anthracnose 
Table 2. Pomological characteristics of genotypes

\begin{tabular}{|c|c|c|c|c|c|c|c|c|c|c|}
\hline Genotypes & $\begin{array}{l}\text { Width } \\
(\mathrm{mm})\end{array}$ & $\begin{array}{l}\text { Length } \\
(\mathrm{mm})\end{array}$ & $\begin{array}{c}\text { Nut cheek } \\
(\mathrm{mm})\end{array}$ & $\begin{array}{c}\text { Nut weight } \\
\text { (g) }\end{array}$ & $\begin{array}{c}\text { Kernel weight } \\
\text { (g) }\end{array}$ & $\begin{array}{c}\text { Kernel ratio } \\
(\%)\end{array}$ & Kernel colour & $\begin{array}{l}\text { Shell thickness } \\
\quad(\mathrm{mm})\end{array}$ & $\begin{array}{l}\text { Ease of } \\
\text { kernel's } \\
\text { removal }\end{array}$ & $\begin{array}{c}\text { Empty } \\
\text { kernel } \\
\text { percent } \\
(\%)\end{array}$ \\
\hline Y1 & $33.84 \pm 1.87$ & $39.23 \pm 4.56$ & $35.06 \pm 2.52$ & $14.32 \pm 1.87$ & $7.28 \pm 0.83$ & 50.84 & Light & $1.56 \pm 0.14$ & Easy & 0 \\
\hline $\mathrm{Y} 2$ & $29.96 \pm 1.25$ & $39.88 \pm 1.61$ & $28.21 \pm 1.17$ & $10.40 \pm 0.75$ & $4.27 \pm 0.59$ & 41.06 & Very light & $1.77 \pm 0.23$ & Difficult & 0 \\
\hline Y3 & $30.63 \pm 1.94$ & $41.50 \pm 2.67$ & $30.27 \pm 2.66$ & $9.96 \pm 1.95$ & $4.25 \pm 0.56$ & 42.67 & Very light & $1.40 \pm 0.21$ & Easy & 0 \\
\hline Y4 & $30.55 \pm 1.38$ & $32.97 \pm 0.86$ & $33.92 \pm 1.54$ & $8.16 \pm 0.77$ & $4.32 \pm 1.37$ & 53.00 & Light & $1.07 \pm 0.22$ & Very easy & 8 \\
\hline Y5 & $30.45 \pm 1.62$ & $38.21 \pm 2.09$ & $31.09 \pm 2.07$ & $8.98 \pm 1.21$ & $4.70 \pm 0.70$ & 52.34 & Light & $0.99 \pm 0.20$ & Very easy & 0 \\
\hline Y6 & $28.37 \pm 1.92$ & $31.80 \pm 2.05$ & $32.57 \pm 1.91$ & $8.01 \pm 2.07$ & $3.99 \pm 1.77$ & 49.81 & Light & $1.18 \pm 0.15$ & Medium & 15 \\
\hline $\mathrm{Y} 7$ & $31.30 \pm 1.16$ & $34.72 \pm 1.12$ & $32.86 \pm 1.22$ & $11.42 \pm 0.73$ & $3.77 \pm 1.17$ & 33.01 & Light & $1.90 \pm 0.17$ & Medium & 8 \\
\hline Y8 & $29.45 \pm 1.91$ & $37.77 \pm 3.29$ & $30.95 \pm 1.75$ & $9.16 \pm 2.27$ & $3.97 \pm 1.57$ & 43.23 & Very light & $1.48 \pm 0.22$ & Easy & 6 \\
\hline Y9 & $29.81 \pm 1.07$ & $34.56 \pm 1.21$ & $31.99 \pm 1.55$ & $10.92 \pm 1.95$ & $5.35 \pm 2.13$ & 48.99 & Very light & $1.31 \pm 0.26$ & Medium & 8 \\
\hline Y10 & $32.73 \pm 1.85$ & $37.31 \pm 2.08$ & $36.95 \pm 2.05$ & $10.24 \pm 1.06$ & $4.06 \pm 0.96$ & 39.59 & Medium & $1.48 \pm 0.23$ & Very easy & 0 \\
\hline Y11 & $36.88 \pm 1.57$ & $44.03 \pm 2.10$ & $34.66 \pm 1.57$ & $12.55 \pm 1.64$ & $5.23 \pm 1.76$ & 41.67 & Light & $1.35 \pm 0.21$ & Very easy & 6 \\
\hline Y12 & $32.88 \pm 1.81$ & $37.26 \pm 2.09$ & $34.76 \pm 2.23$ & $12.20 \pm 1.69$ & $5.50 \pm 1.13$ & 45.08 & Light & $1.42 \pm 0.19$ & medium & 0 \\
\hline Y13 & $30.21 \pm 1.49$ & $33.01 \pm 2.26$ & $31.21 \pm 1.41$ & $9.02 \pm 1.25$ & $4.22 \pm 0.77$ & 46.84 & Very light & $1.26 \pm 0.22$ & Easy & 0 \\
\hline Y14 & $33.63 \pm 1.61$ & $42.84 \pm 2.46$ & $34.39 \pm 1.34$ & $12.89 \pm 1.52$ & $6.40 \pm 0.84$ & 49.65 & Light & $1.27 \pm 0.15$ & Very easy & 0 \\
\hline Y15 & $35.90 \pm 1.68$ & $43.26 \pm 2.56$ & $36.49 \pm 1.23$ & $15.09 \pm 2.19$ & $7.37 \pm 1.30$ & 48.67 & Light & $1.39 \pm 0.13$ & Easy & 0 \\
\hline Y16 & $36.39 \pm 2.14$ & $49.37 \pm 2.01$ & $38.26 \pm 1.32$ & $14.10 \pm 1.98$ & $6.08 \pm 1.53$ & 43.15 & Light & $1.12 \pm 0.18$ & Very easy & 0 \\
\hline
\end{tabular}

Table 3. The fatty acid content of superior genotypes

\begin{tabular}{|c|c|c|c|c|c|c|c|}
\hline \multirow{2}{*}{ Genotypes } & \multicolumn{3}{|c|}{ Saturated fatty acids (\%) } & \multicolumn{4}{|c|}{ Unsaturated fatty acids (\%) } \\
\hline & $\mathrm{C} 16: 0$ & C18:0 & C20:0 & $\mathrm{C} 16: 1$ & C18:1 & C20:1 & C18:2 \\
\hline $\mathrm{Y1}$ & $7.37 \mathrm{ab}^{*}$ & $3.70 \mathrm{a}$ & $0.12^{\mathrm{Ns}}$ & $0.12 \mathrm{ab}$ & $30.38 b$ & $0.29 a$ & $58.01 \mathrm{a}$ \\
\hline Y11 & $8.27 \mathrm{a}$ & $3.20 \mathrm{~b}$ & 0.13 & $0.14 \mathrm{a}$ & $30.36 b$ & $0.22 \mathrm{~b}$ & $57.68 \mathrm{a}$ \\
\hline Y14 & $6.27 \mathrm{~b}$ & $3.23 b$ & 0.11 & $0.05 \mathrm{c}$ & $31.76 b$ & $0.23 b$ & $58.35 \mathrm{a}$ \\
\hline Y15 & $7.28 \mathrm{ab}$ & $3.75 a$ & 0.12 & $0.10 \mathrm{~b}$ & $30.63 b$ & $0.23 b$ & $57.98 \mathrm{a}$ \\
\hline Y16 & $5.75 b$ & $3.86 \mathrm{a}$ & 0.13 & $0.009 \mathrm{~b}$ & $48.43 a$ & $0.25 \mathrm{ab}$ & $41.48 b$ \\
\hline
\end{tabular}

${ }^{*}$ Values within by the same letter are not significantly different at $P<0.05$ by Duncan

${ }^{* *} \mathrm{~N} s$ : not significant

In previous studies some phenolic acids were determined in walnuts kernel, pellicle and leaves (Colaric $e t$ al., 2005; Solar et al., 2006; Pereira et al., 2007; Slatnar et al., 2015; Persic et al., 2018). It is reported that, syringic, caffeic, ferulic, vanillic, gallic, protocatechuic and phenylacetic acid are found in walnut kernels (Prased, 2003). In addition, Colaric et al. (2005) reported that walnut kernels contained chlorogenic, p-coumaric, sinapic, ellagic, juglone and syringaldehyde acid in different quantities. In the present study, propyl-paraben, 4-hydroxybenzoic acid, gallic acid, syringic acid, chlorogenic acid, protocatechuic acid, vanillic acid, caffeic acid, and ferulic acid were identified in the walnut kernel (Table 3). Variations of phenolics in superior genotypes were determined and statistically significant differences were found with Duncan's test, $p<0.05$ ) among genotypes. Propylparaben was the major phenolic among the examined phenolic acids in all genotypes and Y16 had the highest amount of propylparaben $(128.08 \mathrm{mg}$ per $\mathrm{kg})$ in kernel among all genotypes on the contrary other phenolics. Compared to Y1 and Y11, Y14 and Y15 had lowest contents of phenolics also Y16 poor in terms of phenolics except propylparaben. Y11 had the highest amount of 4hydroxybenzoic acid, gallic acid, syringic acid, chlorogenic acid, protocatechuic acid, vanillic acid, caffeic acid, and followed by Y1. The analyses show that Y11 is the most valuable genotype in terms of phenolic acid contents among all superior genotypes.

\section{Organic acids}

Organic acids are found in fruits and vegetables as compounds such as salts, esters, and glycosides. Since the salt elements of these acids are in alkaline form, they are very important for human nutrition (Gundogdu et al., 2014). In the present study, the contents of five superior genotypes were investigated in terms of some organic acids (oxalic, tartaric, formic, malic, malonic, maleic, citric, succinic and fumaric). In literature, there are not enough studies on the organic acid contents of walnuts. Organic acid contents in kernels of superior genotypes were examined in this study and there were statistically significant differences among the genotypes $(p<0.05)$. Citric and malic acids are the most abundant organic acids in walnut kernels. While malic acid is usually found in pome fruit, citric acid is the dominant organic acid of citrus fruits and tartaric acid in grapes. In this research, it was determined that malic acid and tartaric acid were the major organic acids in walnut kernels ranged from 47.88 to $78.51 \mathrm{mg}$ per $100 \mathrm{~g}$ and 30.27 to $49.60 \mathrm{mg}$ per 100 $\mathrm{g}$, respectively. L- ascorbic acid was the third in terms of the amount of organic acids in walnut kernels ranged from 10.71 to $19.71 \mathrm{mg}$ per $100 \mathrm{~g}$. Citric acid was nondetermined in kernels of Y1, Y14 and Y15 but determined at kernels of Y11 and Y16 as 4.51 and $7.55 \mathrm{mg}$ per $100 \mathrm{~g}$, respectively. It was determined that the oxalic, malonic, succinic, maleic and fumaric acid contents ranged from 8.39 to $12.08 \mathrm{mg}$ per $100 \mathrm{~g}, 6.02$ to $9.19 \mathrm{mg}$ per $100 \mathrm{~g}, 2.86$ to $5.32 \mathrm{mg}$ per $100 \mathrm{~g}, 0.26$ to $3.00 \mathrm{mg}$ per $100 \mathrm{~g}, 0.26$ to 0.58 mg per $100 \mathrm{~g}$, respectively (Table 5). 
1098

Table 4. Phenolic acid content of superior genotypes ( $\mathrm{mg} / 100 \mathrm{~g})$

\begin{tabular}{ccccccccccc}
\hline & $\begin{array}{c}\text { Propyl- } \\
\text { paraben }\end{array}$ & $\begin{array}{c}\text { 4-Hydroxy } \\
\text { benzoic }\end{array}$ & Gallic & Syringic & Chlorogenic & $\begin{array}{c}\text { Proto- } \\
\text { cathuric }\end{array}$ & Vanillic & Caffeic & Ferulic \\
\hline Y1 & $117.40 \mathrm{c}^{*}$ & $34.17 \mathrm{a}$ & $9.70 \mathrm{~b}$ & $10.99 \mathrm{a}$ & $8.58 \mathrm{a}$ & $5.77 \mathrm{ab}$ & $4.26 \mathrm{ab}$ & $3.27 \mathrm{a}$ & $2.61^{\mathrm{NS}}$ \\
Y11 & $122.05 \mathrm{~b}$ & $36.04 \mathrm{a}$ & $12.42 \mathrm{a}$ & $10.50 \mathrm{a}$ & $10.33 \mathrm{a}$ & $6.61 \mathrm{a}$ & $6.39 \mathrm{a}$ & $4.02 \mathrm{a}$ & 2.32 \\
Y14 & $112.17 \mathrm{~d}$ & $15.14 \mathrm{~b}$ & $4.17 \mathrm{c}$ & $2.33 \mathrm{~b}$ & $3.64 \mathrm{~b}$ & $\mathrm{Nd}$ & $0.96 \mathrm{c}$ & $0.36 \mathrm{~b}$ & 2.17 \\
Y15 & $111.00 \mathrm{~d}$ & $10.12 \mathrm{c}$ & $5.07 \mathrm{c}$ & $3.06 \mathrm{~b}$ & $5.28 \mathrm{~b}$ & $3.23 \mathrm{bc}$ & $1.68 \mathrm{c}$ & $0.88 \mathrm{~b}$ & 1.61 \\
Y16 & $128.08 \mathrm{a}$ & $17.06 \mathrm{~b}$ & $4.34 \mathrm{c}$ & $3.20 \mathrm{~b}$ & $4.41 \mathrm{~b}$ & $1.63 \mathrm{c}$ & $2.60 \mathrm{bc}$ & $\mathrm{Nd}$ & 2.09 \\
\hline${ }^{*} \mathrm{~V}$
\end{tabular}

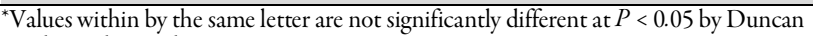

${ }^{* *} \mathrm{Nd}$ : not detected

${ }^{* * *} \mathrm{~N}$ s: not significant, nd: non-detected

Table 5. Organic acid content of superior genotypes $(\mathrm{mg} / 100 \mathrm{~g})$

\begin{tabular}{cccccccccc}
\hline & Malic & Tartaric & L-Ascorbic & Oxalic & Malonic & Succinic & Citric & Maleic & Fumaric \\
\hline Y1 & $47.88 \mathrm{~d}^{*}$ & $30.27 \mathrm{c}$ & $15.30 \mathrm{~b}$ & $8.39 \mathrm{~b}$ & $6.72 \mathrm{~b}$ & $2.86 \mathrm{c}$ & Nd & $0.26 \mathrm{~b}$ & $0.26 \mathrm{~b}$ \\
Y11 & $62.26 \mathrm{c}$ & $49.20 \mathrm{a}$ & $10.71 \mathrm{c}$ & $12.08 \mathrm{a}$ & $6.42 \mathrm{~b}$ & $4.36 \mathrm{ac}$ & $4.51 \mathrm{~b}$ & $0.79 \mathrm{~b}$ & ND \\
Y14 & $78.51 \mathrm{a}$ & $35.08 \mathrm{~b}$ & $14.88 \mathrm{~b}$ & $9.62 \mathrm{ab}$ & ND & $5.32 \mathrm{a}$ & ND & $0.56 \mathrm{~b}$ & ND \\
Y15 & $67.21 \mathrm{~b}$ & $47.44 \mathrm{a}$ & $19.37 \mathrm{a}$ & $11.51 \mathrm{a}$ & $6.02 \mathrm{~b}$ & $3.31 \mathrm{bc}$ & ND & $1.46 \mathrm{ab}$ & $0.43 \mathrm{ab}$ \\
Y16 & $69.31 \mathrm{~b}$ & $49.60 \mathrm{a}$ & $19.71 \mathrm{a}$ & $10.53 \mathrm{ab}$ & $9.19 \mathrm{a}$ & $4.93 \mathrm{ab}$ & $7.55 \mathrm{a}$ & $3.00 \mathrm{a}$ & $0.58 \mathrm{a}$ \\
\hline
\end{tabular}

${ }^{*}$ Values within by the same letter are not significantly different at $P<0.05$ by Duncan

${ }^{*} \mathrm{ND}$ : non-detected

\section{Conclusions}

In the study some morphological, pomological and phytochemical investigations were examined and significant differences were found among genotypes. As a result of weighted ranking methods, 5 genotypes were determined as superior. In order to make more objective evaluations related to plant characteristics, plants should be grown on the same location and same rootstocks to register them as cultivar.

\section{Acknowledgements}

This study was financially supported by Yozgat Bozok University Scientific Research Projects Division (Project number: 6602c-ZF/17-131). We thank Yozgat Bozok University Scientific Research Projects Division for its additions.

\section{Conflict of Interest}

The authors declare that there are no conflicts of interest related to this article.

\section{References}

Akca Y, Koroglu E (2005). Study on selection of superior walnut types in Iskilipwalnut populations. Bahce Ceviz 34(1):41-48.

Akca Y, Ozgen M, Erturk U, Ercisli S (2012). The effects of AVG and GA treatments on pistillate (female) flower abortion in 'Sebin' walnut cultivar. Acta Scientiarum Polonorum Hortorum Cultus 11(4):179185.

Anderson KJ, Teuber SS, Gobeille A, Cremin P, Waterhouse AL, Steinberg FM (2001). Walnut polyphenolics inhibit in vitro human plasma and LDL oxidation. The Journal of Nutrition 131(11):2837-2842.

AOAC (1990). Official Methods of Analysis of the Association of Official Analytical Chemists, 15th edition. In: Helrich K(Ed). Section 969.33.
Asma BM (2012). Pomological and phenological characterization of promising walnut (Juglans regia L.) genotypes from Malatya, Turkey. ActaScientiarum Polonorum Hortorum Cultus 11(4):169-178.

Bhandari MR, Kawabata J (2004). Organic acid, phenolic content and antioxidant activity of wild yam (Dioscorea spp.) tubers of Nepal. Food Chemistry 88(2):163-168.

Bligh EG, Dyer WJ (1959). A rapid method of total lipid extraction and purification. Canadian Journal of Biology and Physics 37:911-917.

Colaric M, Veberic R, Solar A, Hudina M,Stampar F (2005). Phenolic acids, syringaldehyde, and juglone in fruits of different cultivars of Juglans regia L.Journal of Agricultural and Food Chemistry 53(16):6390-6396.

Crews C, Hough P, Godward J, Brereton P, Lees M, Guiet S, Winkelmann W (2005).Study of the main constituents of some authentic walnut oils. Journal of Agricultural and Food Chemistry 53(12):4853-4860.

Caglarirmak N (2003). Biochemical and physical properties of some walnut genotypes (Juglans regia L.). Food/Nahrung 47(1):28-32.

FAO (2018). FAOSTAT Production Crops. Retrieved 2019 February 14 from http://www.fao.org/faostat/en/\#data/QC.

Ersoy N, Gundogdu M, Ercisli S (2017). Evaluation of European cranberry bush (Viburnum opulus L.) genotypes for agro-morphological, biochemical and bioactive characteristics in Turkey. Folia Horticulturae 29(2):179-186.

Ersoy N, Kalyoncu IH, Citil OB, Yilmaz S (2018). Comparison of the fatty acid compositions of six cornelian cherry (Cornus mas L.) genotypes selected from Anatolia. Erwerbs-Obstbau 61(1):67-70.

Fukuda T, Ito H, Yoshida T (2003). Antioxidative polyphenols from walnuts (Juglans regia L.). Phytochemistry 63(7):795-801.

Gharibzahedi SMT, Mousavi SM, Hamedi M, Khodaiyan F (2014). Determination and characterization of kernel biochemical composition and functional compounds of Persian walnut oil. Journal of Food Science and Technology 51(1):34-42.

Guliyev N, Sharifova S, Ojaghi J, Abbasov M, Akparov Z (2018). Genetic diversity among melon (Cucumis meloL.) accessions revealed by morphological traits and ISSR markers. Turkish Journal of Agriculture 
andForestry $42(6): 393-401$.

Gundogdu M, Ozrenk K, Ercisli S, Kan T, Kodad O, Hegedus A (2014). Organic acids, sugars, vitamin $\mathrm{C}$ content and some pomological characteristics of eleven hawthorn species (Crataegus spp.) from Turkey. Biological Research 47(1):21.

Gunduz K, Ozbay H (2018). The effects of genotype and altitude of the growinglocation on physical, chemical, and phytochemical properties of strawberry. Turkish Journal of Agriculture and Forestry 42(3):145-153.

Halász J, Pedryc A, Ercisli S, Yilmaz KU, Hegedus A (2010). S-genotyping supports the genetic relationships between Turkish and Hungarian apricot germplasm. Journal of the American Society for Horticultural Science 135(5):410-417.

Keles H, Akca Y, Ercisli S (2014). Selection of promising walnut genotypes (Juglans regia L.) from inner Anatolia. Acta Scientiarum PolonorumHortorum Cultus 13(3):167-175.

Leslie CA, McGranahan GH (1988). The origin of the walnut. Walnut production manual. The University of California, Division of Agriculture and Natural Resources 3373:3-8.

McGranahan GH, Leslie C (2012). Walnut. In: Badenes ML, Byrne DH (Eds). Fruit breeding. Springer, New York.

Liu P, Yang B, Kallio H(2010). Characterization of phenolic compounds in Chinese hawthorn (Crataegus pinnatifida Bge. var. major) fruit by highperformance liquid chromatography-electrospray ionization mass spectrometry. FoodChemistry 121(4):1188-1197.

Mitrovic M, Stanisavljevic M, Danjanov JG (1997). Biochemical composition of fruits of some important walnut cultivars and selections. Acta Horticulturae 442:205-207.

Nettleton JA (1995). Omega-3 fatty acids and health. Springer, Boston, MA pp 6476.

Ozkan G, Koyuncu MA (2005). Physical and chemical composition of some walnut (Juglans regia $\mathrm{L}$ ) genotypes grown in Turkey. Grasas y Aceites 56(2):141-146.

Ozturk N, Tuncel M (2011). Assessment of phenolic acid content and in vitro antiradical characteristics of hawthorn. Journal of Medicinal Food 14(6):664-669.

Pereira JA, Oliveira I, Sousa A, Valentão P, Andrade PB, Ferreira IC, Estevinho L (2007). Walnut (Juglans regia L.) leaves: phenolic compounds, antibacterial activity and antioxidant potential of different cultivars. Foodand Chemical Toxicology 45(11):2287-2295.
Pereira JA, Oliveira I, Sousa A, Ferreira IC, Bento A, Estevinho L (2008). Bioactive properties and chemical composition of six walnuts (Juglans regia L.) cultivars. Food and Chemical Toxicology 46(6):2103-2111.

Persic M, Mikulic-Petkovsek M, Slatnar A, Solar A, Veberic R (2018). Changes in phenolic profiles of red-colored pellicle walnut and hazelnut kernel during ripening. Food Chemistry 252:349-355.

Poggetti L, Ferfuia C, Chiabà C, Testolin R, Baldini M (2017). Kernel oil content and oil composition in walnut (Juglans regia L.) accessions from north-eastern Italy. Journal of the Science of Food and Agriculture 98(3):955-962.

Polonik SG, Prokofieva NG, Agafonova IG, Uvarova NI (2003). Antitumor and immunostimulating activity of 5-hydroxy-1,4 naphthoquinone (juglone) $\mathrm{O}$ - and S-acetyl gycoside. Pharmaceutical ChemistryJournal 37(8):397-398.

Prasad RBN (2003). Walnuts and pecans. In: Caballero B, Trugo LC, Finglas PM (Eds). Encyclopaedia of food sciences and nutrition. 2nd ed. Academic Press: London, U.K. pp 6071-6079.

Sehirali S, Ozgen M (1987). Plant genetic resources. Publication of Ankara University Agricultural Faculty No: 1020. Ankara pp 294.

Serce S, Ercisli S, Sengul M, Gunduz K, Orhan E (2010). Antioxidant activities and fatty acid composition of wild grown myrtle (Myrtus communis L.) fruits. Pharmacognosy Magazine 6(21):9-12.

Slatnar A, Mikulic-Petkovsek M, Stampar F, Veberic R, Solar A (2015). Identification and quantification of phenolic compounds in kernels, oil and bagasse pellets of common walnut (Juglans regia L.). Food Research International 67:255-263.

Solar A, Colarič M, Usenik V, Stampar F (2006). Seasonal variations of selected flavonoids, phenolic acids and quinones in annual shoots of common walnut (Juglansregia L.). Plant Science 170(3):453-461.

Tariq M, Ali S, Ahmad F, Ahmad M, Zafar M, Khalid N, Khan MA (2011). Identification, FT-IR, NMR (1H and 13C) and GC/MS studies of fatty acid methyl esters in biodiesel from rocket seed oil. Fuel Processing Technology 92(3):336-341. 